\title{
THE "BASE MAP" FOR URBAN PLANNING: CARTOGRAPHIC REPRESENTATION AS A FUNDAMENTAL TOOL FOR THE REPRESENTATION OF THE TOWN PLAN
}

\author{
Jordi GOMIS ${ }^{1}$, Carlos TURÓN ${ }^{1}$
}

DOI: 10.21163/GT_2018.131.06

\begin{abstract}
:
Topographic information of the territory is essential in many areas of the sciences, especially in those involving the discipline of Geography in its broadest sense and aspects. However, the cartographic representation of the territory can be considered the 'first' drawing of the long process of the urban planning project. Without this 'first' drawing, the town planner is unable to deal with this task of planning satisfactorily. The proper representation of the morphology, or if you prefer, the geomorphology of the territory and of the elements and objects it 'supports and contains', is manifested in the cartographic representation that the architect or urban planner needs to define their proposed planning. This article discusses 'the graphic evolution' of these first and necessary 'base maps', from a purely instrumental point of view and from one of the visual perception of the solutions adopted, focusing on urban plans drafted in the last four decades.
\end{abstract}

Key-words: Graphic representation, Technical drawing, Urban Planning, City drawing, Urbanism, Cartography.

\section{INTRODUCTION}

It is a requirement and a need for all planning work to dispose of enough knowledge of the place where it is to be implemented. For the same reason, for their performance, urban and spatial planning will require knowledge that should cover all the factors involved in the process of the growth and extension of the city, and how the territory is used in general (Esteban, 2007). Often as a basis for intervention, the map, whether it is of networked relationships or a geographically precise location, precedes the plan (Desimini \& Waldheim, 2016). The base map, with its corresponding representation of the topography of the territory, shows the physical reality of the area where the new city plan is to be implemented. This physical reality is expressed through cartography, an absolutely essential component and probably the most important of all those comprising the information necessary for carrying out urban planning (Bosselman, 1997).

The effectiveness of this cartography will depend, primarily, on the quality, scale and type of plans that are used (Aradillas \& Cabezas, 1992). It should be noted that the quality of cartography varies depending on the amount of information contained in the maps, the reliability of this information and, of course, the graphic quality of the drawing. Regarding the scales of the maps, they depend specifically on the nature and scope of each particular task (École national des sciences geographiques, 1999). In the study of our concern, the scale is determined mainly by the choice made by the technician when commissioning the base map on which s/he has to work. In the case of the sample analysed, the scales are, basically,

\footnotetext{
${ }^{1}$ Universitat Rovira i Virgili, Tarragona, Spain, jordi.gomis@urv.cat,carlos.turon@urv.cat
} 
1:5,000 and 1:1,000. In most cases, these scales allow one to appreciate the whole urban centre and its physical relationship with its immediate surroundings and deal precisely with the urban fabric in order to refine and adjust specific urban planning actions. In urban planning, the city plan is defined by means of zonal delimitations that must be appropriately accurate according to the different sense of each of the urban development systems. In this case, the assessment of cartographic precision is absolutely essential. However, we also find authors that specify the need and requirement that nowadays, and with the means that are available, the imprecisions in the representation of the base map affected by urban planning are not acceptable under any circumstances, and can only lead to unwanted conflicts that slow down the implementation of plans. In any case, it is clear that the precise and unambiguous definition of the territory where the urban development is to take place or of its various scopes is a strictly necessary element of any planning and that, of course, it must be rigorously represented in the planning drawings manifestly and clearly (Dondis \& Gonzalez, 1976). In this case, cartography and its representation becomes a fundamental tool for planners and architects. In fact, several most interesting theoretical studies, such as for example the one by Cattor and Perkins (Cattor \& Perkins, 2014), look in depth at the study of alternative spatial models applied to a wide range of scales and in very different contexts of representation, often even, a long way from the normal scales of representation of common urban development plans.

However, too often the real problems of the graphic coding and of the visual perception of the plan are forgotten and a great deal of attention is given to aspects that are too instrumental and that diverge from pure graphic representation and its visual result (Deforge, 1975). All too often, the real problems of town planning drawings that are really executed and put at the disposal of the citizens who consult them, and/or the municipal technical services that develop them, are ignored. Often, too much attention and debate are given to plans that, published in books and journals due to their intrinsic disciplinary interest, their special territorial dimension or, why not, the pure brilliance of the urban planner, digress from the ordinary and common task of urban planning and its daily management. It is, therefore, this specific language, this particular graphic representation that is used by so many 'non-theoretical' architects and urban planners, that is to say, those who finally draw up and sign planning works that mostly become tangible realities, which is what this paper aims to explore. The present study aims to analyse the graphic systems that planners have used to represent the cartography of planning areas from an especially visual point of view, through an evolutionary and historical review of the different graphic solutions used by technicians. Unfortunately, and given the logical limited length of this article, it is not possible to present either the methodology or the detailed results obtained in the research, believing it far more interesting to relate the findings with which the research has provided its authors. It should be pointed out, however, that that the study sample of maps spans from the last decades of the 19th century until 2015.

\section{THE REPRESENTATION OF TOPOGRAPHY AND THE BASE MAP}

The representation of the topography and the base map has remained constant especially since the beginning of so-called 'modern urbanism'. The processes of representing the territory, which logically have served as the basis for drawing the new arrangements and designed planning, have undergone few graphic modifications, although they have improved substantially in terms of technical execution, end results and accuracy. Descriptive plans of the city and its surroundings, with a more accurate representation of the territory, had been 
developed and began to be present in many representations of cities in the 18th century, where even buildings within the blocks of the cities and also properties and suburban properties and fields were represented (Fig. 1).

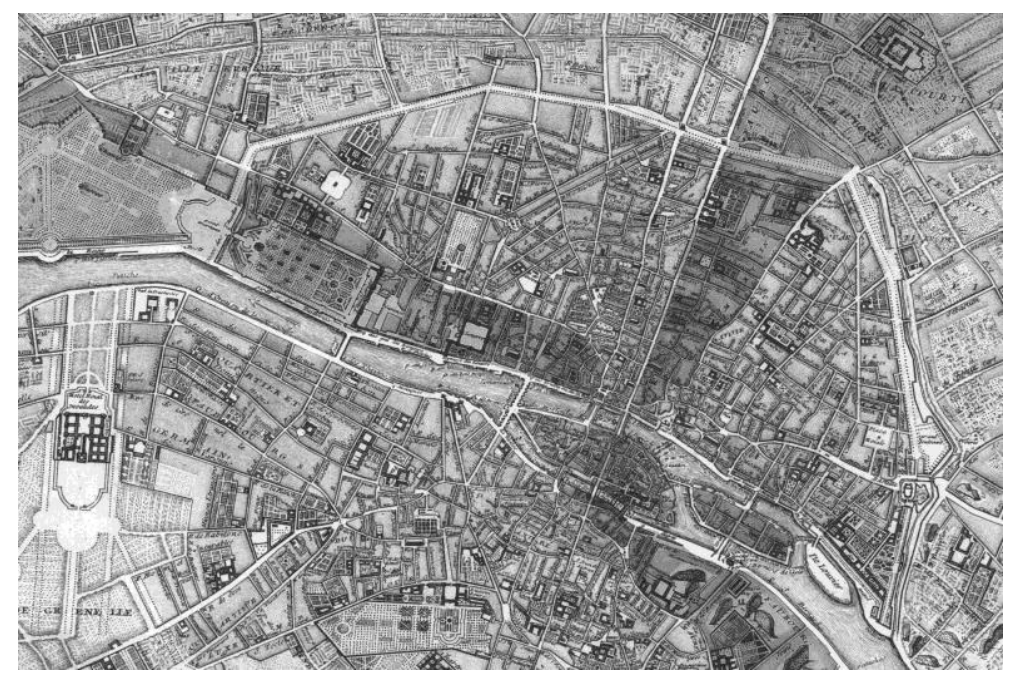

Fig. 1. Part of the map of Paris in 1740, by Jean Delagrive (1689-1757) (Sambrico, 1990).

However, for the purposes of their graphic analysis, it must be borne in mind that these historical maps often suffered geometric deformations and other degradations during their conservation and others caused by acquisition (scanning) (Baiocchi \& Maurizio, 2000). But also, the rigorous georeferencing of historical cartography allows for the spatial comparison with current cartographies and with very high resolution satellite images, and the consequent analysis of the urban structure and its formal and functional contents (Baiocchi et al, 2013).

Topography, as we understand it today, with the representation of contours and auxiliary data on survey points and heights, appeared in the late 19th and early 20th century. In earlier plans, the geographical aspects were limited to indicating coasts, gullies, rivers, marsh areas, significant elevations, etc. It was after the development of photographic surveying that, with the help of primitive aerial photos assisted and completed with data from specific tachymetric surveys, topographic maps of large areas of the territory became generalized. These maps are perfectly suitable for technicians to approach new growth and urban development projects with greater accuracy and reliability. They are maps in which the topography of the region is shown by contours, thus becoming an especially valuable tool for the technician. Maps that, on semi-transparent or opaque paper, were used either as a basis, using various techniques, for superimposing the new proposals put forward. Graphic techniques to modify and add new planning to base maps ranged from the use of coloured pencil or tempera paints, and 'gouache', if drawn on opaque copies of the base map (Fig. 2), to the use of conventional ink, if the plan was presented in black and white on transparent or semi-transparent paper (Zell, 2008). 


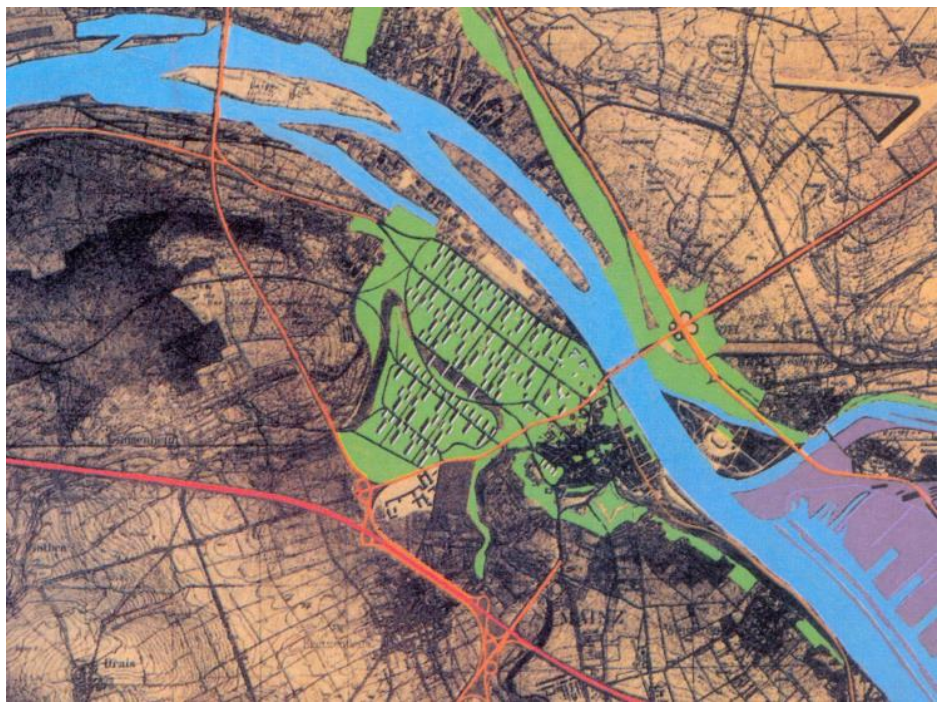

Fig. 2. Project of the Mainz reconstruction plan (Germany) - by means of linear apartment blocks, designed by the architect M. Lods in 1947. 'Gouaches' on map printed on cardboard

(Bosma \& Hellinga 1997).

As for cadastral maps, in which topographical issues are often of secondary nature, the tachymetric survey was the usual technique, and the use of blueprints on paper of different transparency was chosen to work on in preference due to being easy to modify. It should not be overlooked that cadastral maps are often made to a scale at which the degree of detail is greater and, therefore, it is common that, if a photographic survey exists, it is checked, complementing it with a cadastral study. Graphically, the base map and topography are generally drawn using fine lines. It can be seen how at the end of the 19th century and until after the first half of the 20th century there was a tendency to use types of thicknesses closer to the group or range of $0.8 \mathrm{~mm}$ and of $1.2 \mathrm{~mm}$ (Corbella 1983). This feature, applicable, as we shall see, to many of the aspects analysed, probably is more closely related to the drawing utensils and tools that existed at the time of drawing than the conscious decision of the designer or draughtsman (Piedmont-Palladino, 2007).

We will see how, as drawing tools and techniques evolved the thickness with which the graphic resources finally applied decrease visibly. As the map and the representation of the topography are essentially to help with the final representation of the planned design, graphically it is usually approached with fine lines and small text size so as not to 'dirty' and clutter the drawing. Only the lines used to represent the 'principal contours' are usually drawn more thickly, but never exceeding a thickness of more than 0.4 or $0.5 \mathrm{~mm}$. Naturally, to say that the base map provides 'additional' information does not mean that it does not involve some transcendent and necessary data that the technician must analyse and assess for consideration in the definition of the proposed city plan. It is also clear that due to the drawing techniques and tools available at the time, every attempt was made to avoid dashes and/or dots to save time and avoid errors. Only a few technicians use topographic representation as a sufficiently significant graphic instrument, which makes its presence and notoriety deliberate in the representation of the idea of the planning they have created (Fig. 3). 


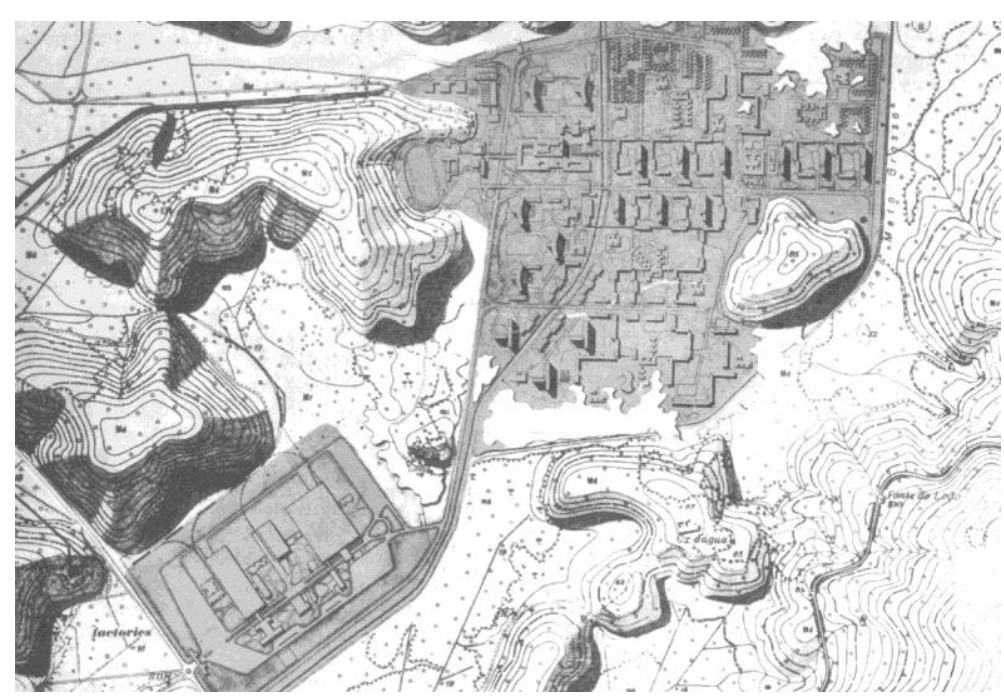

Fig. 3. Ground plan of 'Cidade dos Motores' in Brazil. This new city was designed by J.L. Sert in 1945. It is a city between Rio de Janeiro and Petropolis which was planned for 25,000 people. Intentionally J.L. Sert sought to leave the hills surrounding the city full of vegetation, concentrating the construction in the flat regions of the land and this is what he wanted to show with the excessively highlighted representation of the topography of the hills (Freixa \& Rosolia, 1981).

\section{GRAPHYC DEVELOPMENT}

\subsection{Period 1980-1989}

Main graphic characteristics of the period 1980-1989:

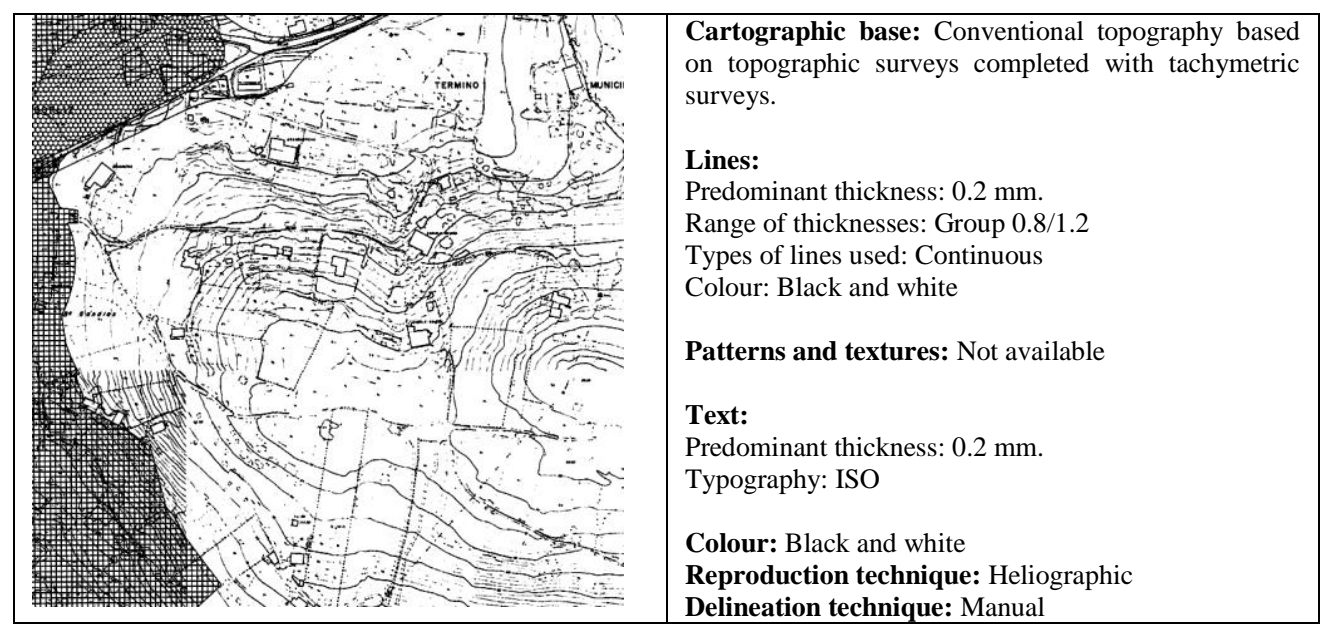

Fig. 4. Representative example of the graphic font of the period 1980-1989 (Author's file). 


\subsection{Period 1990-1999}

Main graphic characteristics of the period 1990-1999:

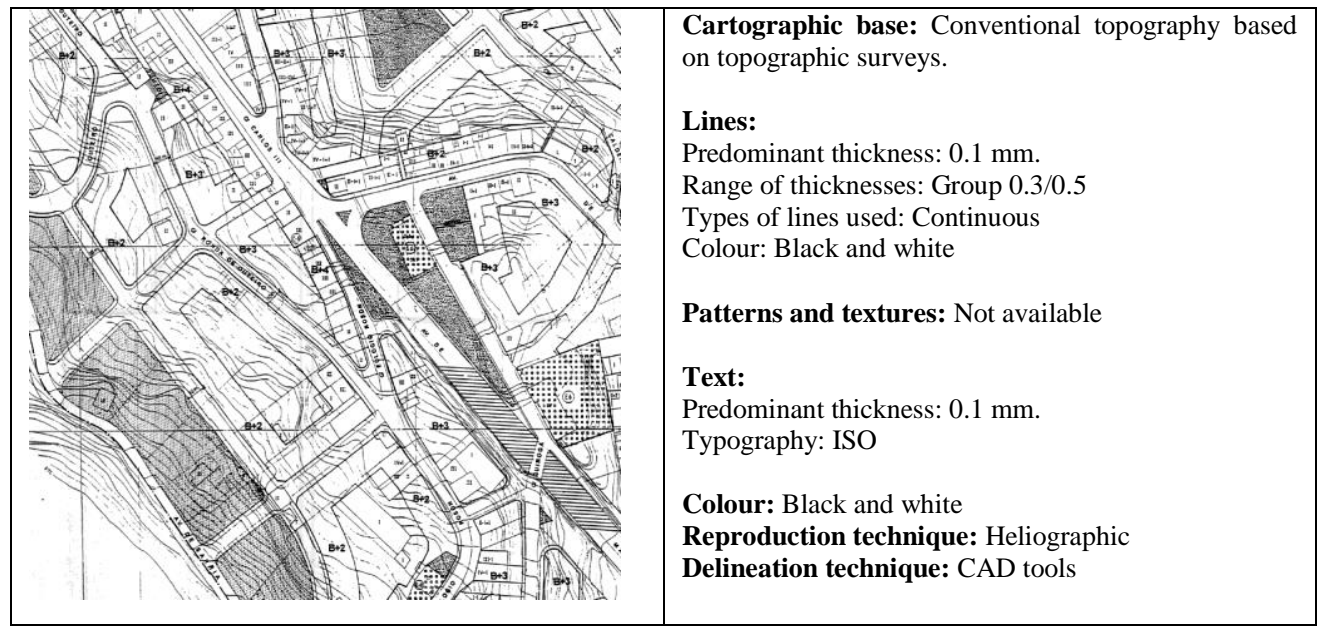

Fig. 5. Representative example of the graphic font of the period 1990-1999 (Author's file).

\subsection{Period 2000-2015}

Main graphic characteristics of the period 2000-2015:

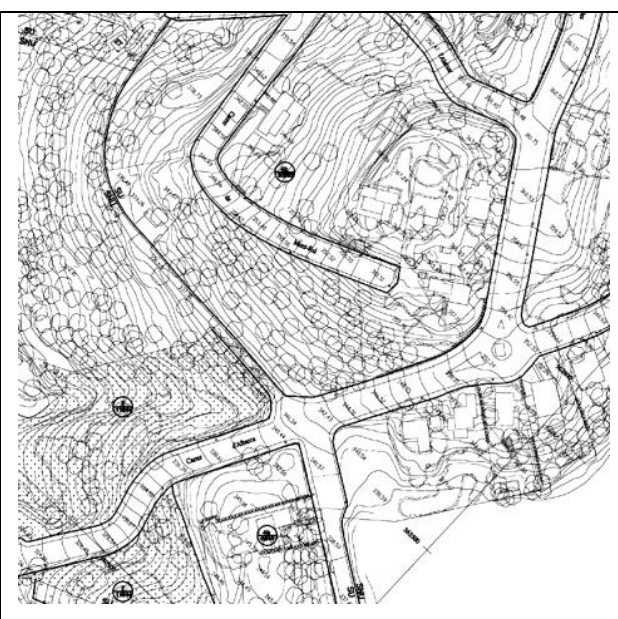

Cartographic base: Conventional topography based on topographic surveys.

\section{Lines:}

Predominant thickness: $0.1 \mathrm{~mm}$.

Range of thicknesses: Group 0.3/0.5

Types of lines used: Continuous

Colour: Black and white

Patterns and textures: Not available

Text:

Predominant thickness: $0.1 \mathrm{~mm}$.

Typography: ISO

Colour: Black and white

Reproduction technique: Heliographic

Delineation technique: $\mathrm{CAD}$ tools

Fig. 6. Representative example of the graphic font of the period 1990-1999 (Author's file). 


\section{FINAL CONCLUSIONS: FROM THE 1990s TO THE LASTEST TRENDS}

During the 1990s, CAD tools were to make delineation easier but would also be limited by the systems for printing and reproducing the maps made. While the use of CAD tools facilitated the recovery and the addition of colour to base maps and planning drawings, they were extremely limited, on the one hand, by the existing printing devices, which still worked with varieties of technical pen tips, and, especially, due to the maintenance of the blueprint process of generating copies. These limitations meant that, despite the availability of new drawing tools that allowed enhancing the quality of the work and incorporating colour, it was this latter issue that was sacrificed, due to the limitations that still existed when transferring the drawing onto a 'paper medium'. It should be mentioned, however, that during this period, the drawing tools hitherto used to draw plans disappeared. The templates of letters and symbols or decals of patterns and textures are elements that were quickly eliminated, since the CAD engines and their utilities would render them completely unnecessary.

From the end of the 1990s the use of large format inkjet printers started to become generalized. In this case, generalization meant that their price allowed the incorporation of these printing tools a reasonable cost. Thus, planners could no longer incorporate colour into their plans. And this happened for two reasons: firstly because computer-assisted design programmes have allowed this since some time ago, and secondly, and in this case more decisively, because machines were available that enabled colour printing and copying of the plans that had been drafted, and at a more than acceptable cost. Copying was now replaced by the printing of as many originals as required.

Changes in the fonts used to annotate the various aspects of the plans, the use of several types of lines, the progressive reduction of the general thickness of the lines that provided the precision and clarity of the drawing, the use of colours or thicknesses that keep the base map on a visual second level, etc., are variations on the use of graphic resources that have been implemented and that, seen in their entirety, have brought clear graphic and visual benefits to urban planning drawings. This introduction of changes in instrumental techniques seems not to have finished. Today, consulting on paper has been replaced with consulting on computer screens as well as the use of photoplans. Doubtless there will be new changes in the graphic approach to new urban planning documents. Referring to the new trends observed, it must be stated that the progressive incorporation of colour in urban planning plans has facilitated the inclusion of a great deal of data, especially in base maps, that sensibly, were previously disregarded or ignored in order simplify the map visually.

The help that the nuance of colour may infer in these data now allows its incorporation. The use of the colour grey, which relieves contour lines of their visual impact, even allows the inclusion of data such as 'dot clouds', which now can be added in order topographically and altimetrically to specify concrete and specific areas of the territory, in view of the need for a more accurate study (Fig. 7). This is because the categorization of the land, which is achieved with the addition of colour, makes reading the document and the hierarchy of graphical aspects easier over the topographic and cadastral elements represented.

Maps in which the topographic representation of the terrain is not too important are usually those of rather built-up areas. In these cases, the importance of the base map lies mainly in the sub-divisory or cadastral aspect, with the orography of the territory losing much of its importance and, generally, avoiding its representation. 


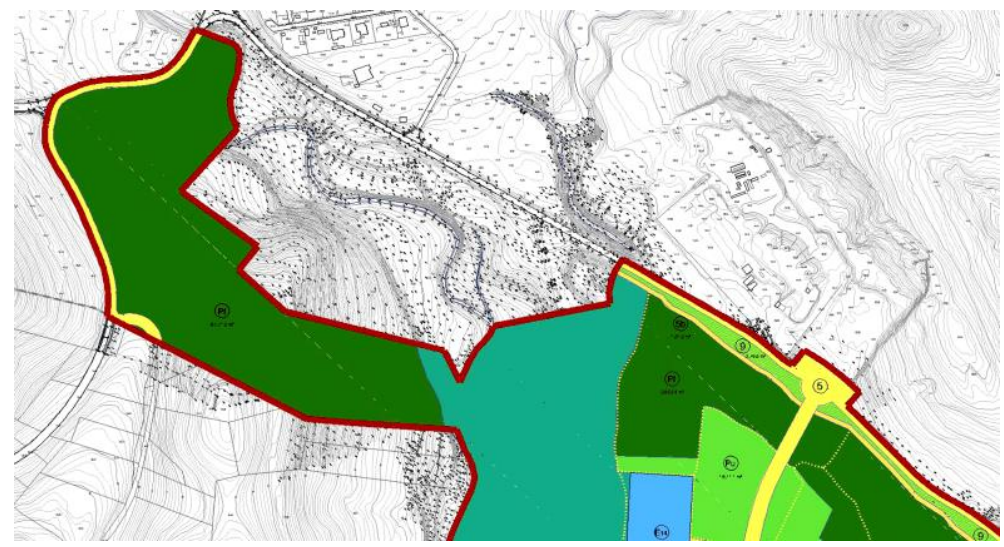

Fig. 7. Part of the land classification map of the Sector 'Pla de Ponent' - Gavà Town Council (CataloniaSpain)- 2008. Observe how the base map includes data -in this case dot clouds- in order topographically to specify certain areas of the territory (Gavà Town Council, 2008).

The mechanisms of representing cadastral and plot data are usually similar to those are used to represent topographic base maps. The addition of colour in maps and drawings clearly shows the planned areas and at the same time categorizes them. The base data are usually represented with very thin lines, or by using the range of greys to reduce their visual importance and not to disturb the observer in their reading and understanding of the map (Fig. 8).

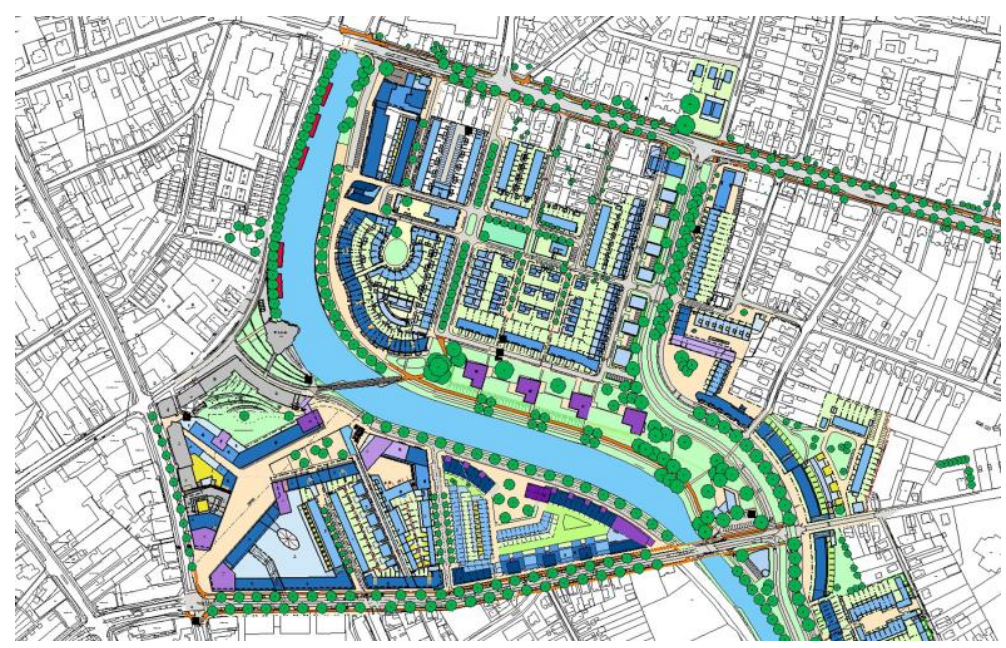

Fig. 8: Plan to renew the district of 'Kanaaloevers' in the Dutch city of 'Apeldoorn', 2008. The base map, basically cadastral and sub-divisory, is drawn using fine lines and in the range of greys (Apeldoorn Town Hall, 2008).

More recently work has also been performed using orthophotoscopic maps as their base map maps, which give a very clear picture of the terrain and, at the same time, of how the project will be superimposed. 
The advantage of this type of drawing is that it shows the viewer very clearly the implementation of what has been planned and how it will be organized on a real image of the territory. For the 'layperson' it is an especially useful resource since it allows visually identifying the region for the future arrangement and, at the same time, enables getting a clear idea, a bird's eye view, of the final outcome of the foreseen planning. However, this type of graphic representation is not, a priori, a widely used tool for the performance of urban planning projects in the development phase, but is rather used as a base map of final plans for presentation or 'layouts'.

To conclude this section, there must be mention of the incorporation of photoplans as base maps. Photoplans are aerial photographs enlarged to the desired size and are basically used to make interpretations of conventional topographic maps.

Recently, it has started to become commonplace for both zoning plans as well as floor plans -Layouts or Master Plans-, to be rendered on the basis of photoplans where, by means of more or less opaque colours, the zonifications, roadways, plots, etc. that have been planned are superimposed. Thus, the town planner will draw on the photograph of the territory all that he wishes to be represented, thus replacing the traditional layout.

Certainly, from a purely technical point of view, the drawing can be considered to lose the clarity and precision that should always be maintained, and it is rather an image intended for the non-specialist that does not allow upholding the necessary level of technical rigour. We must consider that the use of photoplans may pose certain problems in the management of 'extensive graphic information' involved in this 'new' base map Studying in detail the adaptation of the photoplan as a new graphic resource applicable to new ways of presentation, publication and consultation of urban planning work appears to be a field of clear interest to the urban planner (Gomis \& Turón, 2017). Nevertheless, it is a resource that we are seeing increasingly, especially on the urban planning information pages that can be found on the internet. Far more common and available in this new medium than on paper, this type of representation is beginning to set the trend in the new presentations of regional planning.

\section{REFERENCES}

Apeldoorn Town Hall, 2008. Cultural Heritage: Apeldoorn (The Netherlands) [online] Available at: http://www.planum.net/cultural-heritage-the-netherlands [Accessed 23 March 2017]

Aradillas, M. \& Cabezas, F. (1992). Dibujo y sistemas de representación: Planos acotados y dibujo topográfico. Universidad de Sevilla: Escuela universitaria de Ingeniería Técnica Agrícola ed.

Baiocchi V. \& Maurizio C. (2000). Problemi dei calibrazioni di file raster e vettoriali in un sistema informativo territoriale. Bolletino della società italiana di topografia e fotometria. Vol. 1, pp. 23-32.

Baiocchi V., Lelo K., Milone M.V., Mormille M. \& Tanga E. (2013). Knowing the past for managing the present: a comparison between historical cartography and satellite images for the study of Rome's city centre. Geographia Technica, Cluj University Press. Issue 8 No. 1, pp. 17-27.

Bosselmann, P. (1997). Representation of places: Reality and realism in city design. Berkeley, University of California Press.

Bosma, K. \& Hellinga, H. (1997). Mastering the city: North-European city planning 1900-2000. Rotterdam: NAi Publications.

Cattor, B. \& Perkins, C. (2014). Re-cartographies of Landscape: New Narratives in Architectural Atlases. The Cartographic Journal. Volume 51, Issue 2: Cartography and Narratives.

Corbella, D. (1983). Dibujo Técnico. Elementos de normalización. Madrid: Corbella Barrios, David. 
Deforge, Y. (1975). Le graphisme technique. Paris: Université René Descartes.

Desimini, J. \& Waldheim, C. (2016). Cartographic Grounds: Projecting the Landscape Imaginary.

New York NY: Princeton Architectural Press.

Dondis D. \& González J. (1976). La sintaxis de la imagen: Introducción al alfabeto visual. Barcelona: Gustavo Gili.

École nationale des sciencies geographiques (1999). Cartographie -Volume 1-Sémiologie graphique et conception cartographique. Cité Descartes, Champs-sur-Marne: École nationale des sciencies geographiques.

Esteban, J. (2007). L'ordenació urbanística: Conceptes, eines i pràctiques. Barcelona: Diputació Barcelona.

Freixa, J. \& Rosolia, O. (1981). Josep Ll. Sert. Barcelona: Gustavo Gili.

Gavà Town Council (2006). Modifiació del Pla General Municipal/Pla de Ponent. Available at: http://www.gavaciutat.cat/documents/1694232/1730163/04.+Zonificaciomodiplaponent.pdf/7275230f -fce1-43ad-a5ff-e6efc34929ff [Accessed 23 March 2017]

Gomis, J. \& Turón C. (2017). From layout to photoplan: reflections on the "rePRESENTATION" of urban planning. Geographia Technica, 12 (1), pp 57-63.

Piedmont-Palladino, S. (2007). Tools of the Imagination: Drawing tools and technologies from the eighteenth century to the present. New York NY: Princeton Architectural Press.

Sambrico, C. (1990). El "Límite" de la ciudad ilustrada: La ordenación de un espacio urbano. ARQUITECTURA (Revista del Colegio Oficial de Arquitectos de Madrid). Issue SeptemberDecember 1990, No. 286-287 pp. 168-183.

Zell, M. (2008). The architectural drawing course: Understand the principles and master the practices. London: Thames \& Hudson. 